\title{
Clinical and Radiographic Evaluation of the Labial Bone Plate after Using Plasma Rich Fibrin in Immediate Implant in Esthetic zone
}

\section{Original Article}

\author{
Amany Khalifa El-Sayed ${ }^{a}$,Samar Ibrahim Hashem ${ }^{b}$ \\ Department Oral and Maxillofacial Surgery, Faculty of Oral and Dental Medicine, \\ ${ }^{a}$ Modern University for Technology and Information, ${ }^{b}$ Nahda University, Egypt
}

\begin{abstract}
Background: When a dental implant is placed into a fresh extraction socket, a space between the implant periphery and surrounding bone occurs. This gap should be filled specially in the labial side to support inheritably thin labial plate of bone in esthetic zone. Sohn's Poncho technique is a method to utilize the healing capacity of platelet-rich fibrin/concentrated growth factor (PRF/CGF) autologous membranes in an open wound.

Aim of the Study: Clinical and radiographic evaluation of the amount and contour of labial bone plate (LBP) after using plasma rich fibrin by using Sohn's Poncho technique in immediate implant in esthetic zone.

Materials and Methods: Sixteen implants were included in maxillary anterior region in this study $(\mathrm{n}=16)$. They were divided into two groups; group I: Includes eight immediate implants using of plasma rich fibrin (PRF). Group II: Includes eight immediate implant placements without PRF. All implants were evaluated immediately and along six months postoperatively. Evaluation was performed clinically via pink esthetic score (PES) and radiographically by (CBCT) to assess (LBP) thickness and height.

Results: There was no statistically significant difference was recorded $(P>0.05)$ between both groups in all the measured parameters. However, group I was recorded higher scores than group II in all measurements.

Conclusion: (PRF/CGF) may have some benefits in preservation of alveolar bone integrity and improving the esthetic outcome in immediate implant.

Key Words: Alveolar bone preservation, Cone beam computed tomography, Immediate implant, Plasma rich fibrin, Sohn's Poncho technique.

Received: 30 November 2020, Accepted: 24 December 2020.

Corresponding Author: Amany Khalifa El Sayed, Department Oral and Maxillofacial Surgery, Modern University for Technology and Information, Egypt, Tel.: +20226700333, Mobile: +201002436646,

E-mail: dr.amany_khalifa@hotmail.com.
\end{abstract}

ISSN: 2090-097X, January 2021, Vol. 12, No. 1.

\section{INTRODUCTION}

The benefits of immediate implant insertion after tooth extraction are elimination of post-extraction healing period, reduction of the number of surgical sessions, preservation of alveolar width and height and lower risk of dehiscence or fenestrations around dental implant. Moreover, better angulation leading to improved esthetics and axial occlusal loading and improved surgical orientation relative to pertinent anatomical structures were obtained ${ }^{[1]}$.

When an implant is placed in a fresh or recent extraction socket, a gap between the implant surface and the bone walls of the socket may occur. Platelet-rich fibrin (PRF) has been recently proposed as an aid for promoting hard and soft tissue regeneration in the field of oral surgery. It is a simple, natural and inexpensive technique for the production of leukocyte and (PRF) concentrates. PRF is a consistent fibrin biomaterial and not improved fibrin glue from the platelet-rich plasma (PRP) family. (PRF) releases high amounts of growth factors such as transforming growth factor B1 (TGFB-1), platelet-derived growth factorAB (PDGF-AB), vascular endothelial growth factor (VEGF), and matrix glycoprotein such as (thrombospondin-1) during at least 7 days in vitro. Thus, this biomaterial presents a specific biology which offers several advantages including promoting wound healing, bone growth and maturation, graft stabilization, wound sealing and hemostasis, and improving the handling properties of graft materials ${ }^{[2-4]}$.

Sohn's Poncho technique ${ }^{[5]}$ was a method to utilize the healing capacity of (PRF/CGF) autologous membranes in an open wound when performing localized guided bone regeneration techniques. This technique was performed to stabilize the (PRF/GCF) membrane by using a healing abutment or prosthetic abutment at the implant site to perform minimally invasive procedures.

Several clinical factors may influence the aesthetic success of implant-supported prostheses, especially where the aesthetic result is very important, the main risk region being the anterior maxilla. Among the factors that depend on the dental surgeon are the positioning of the implant, the 
manipulation of the soft tissue and the type of prosthesis to be used. There are also factors that depend on each individual that include quantity and quality of the bone and soft tissues. The clinical and imaging evaluation of the condition of the bone structure after extraction shows a loss of alveolar volume shortly after. Therefore, the aesthetic search of implants installed in the anterior maxilla region cannot be easily achieved ${ }^{[5-7]}$.

Crest preservation would aim to minimize resorption of the buccal wall and increase bone formation within the alveolus. The importance of preserving the bone structure is directly linked to the search for aesthetic result, and healthy structures around the implant $\mathrm{t}^{[7,8]}$.

The choice of an accurate and reliable imaging modality in the assessment of peri-implant marginal alveolar bone status is clinically important in terms of postoperative monitoring of stability and selection of remedial treatment. Maxillofacial cone beam computed tomography (CBCT) is a volumetric acquirement technique providing accurate and reliable submillimeter resolution images in all spatial dimensions, which shows promise in the detection of peri-implant defects. Vertical marginal bone loss at the peri-implant surfaces must not be more than $1-2 \mathrm{~mm}$ during the first year of function and $0.2 \mathrm{~mm}$ thenceforth All (CBCT) images performed similarly for the detection of simulated buccal marginal alveolar peri-implant defects. Depth, width and volume measurements of the defects from various (CBCT)images correlated highly with physical measurements ${ }^{[9,10]}$.

The use of reliable indices to evaluate the aesthetic outcomes in the aesthetic area is an important and objective clinical aid to monitor the results overtime. Various indices were proposed to evaluate aesthetic outcomes of implantprosthetic rehabilitation of the anterior area like PeriImplant and Crown Index [PICI], Implant Crown Aesthetic Index [ICAI], Pink Esthetic Score/White Esthetic Score [PES/WES], and Pink Esthetic Score [PES] $]^{[11]}$.

Furhauser et al. 2005 ${ }^{[12]}$ introduced an excellent index termed Pink Esthetic Score (PES) for evaluation of the soft tissue around single-implant crowns that might change overtime; PES could be a useful tool for monitoring longterm soft tissue alterations (Figure 1).

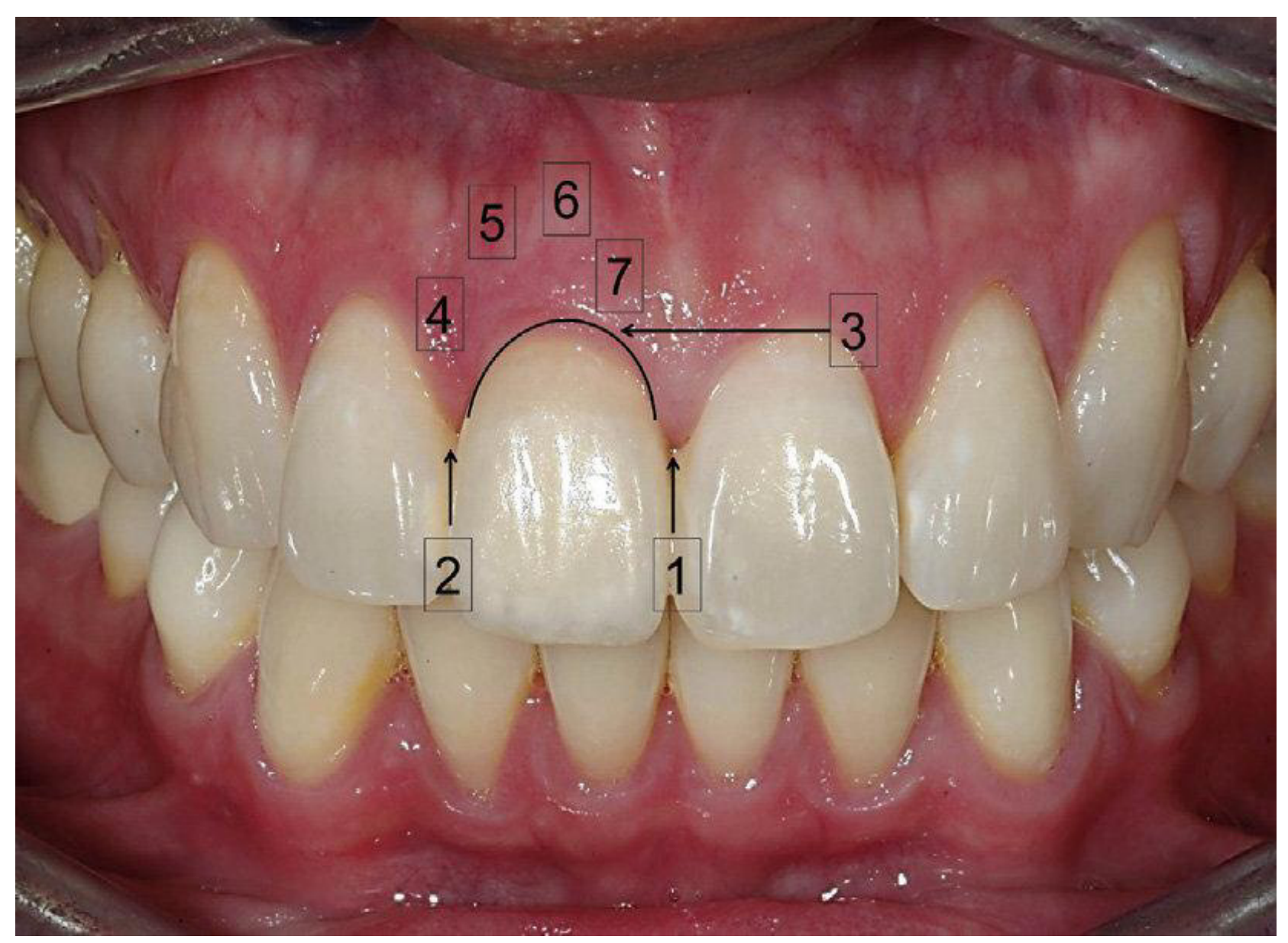

Figure 1: PES assessment (Furhauser et al. (2005) (40)). 


\section{MATERIALS AND METHODS}

Sixteen patients seeking for dental rehabilitation of freshly extracted socket in maxillary anterior region. Patients were randomly allocated to one of two main groups. Group I (study Group) consisting of eight immediate implant placements with PRF, and Group II (control Group) consisting of eight immediate implant placements without PRF. Patients were recruited from those attending the implant clinic affiliated to the Oral and Maxillofacial Surgery Department, Faculty of Dentistry, Ain shams University. Before conduction of this study, the research protocol was reviewed and approved by the Research Ethical Committee. All prospective candidates were provided with an informed consent.

\section{I- Preoperative preparation:}

Patient's data were collected; name, gender and age, medical and dental histories were taken and the oral mucosa of the edentulous area was examined by inspection and palpation. Also, all patients underwent standardized periapical radiography to detect any periapical pathology. Pre-operative (CBCT) scan (ICAT machine, Imaging Sciences International, Hatfield, PA, U.S.A) was performed at the department of Oral Radiology, Faculty of Dentistry, and Ain Shams University. (CBCT) was done to assess; the thickness of labial bone plate (LBP), the amount of bone available apical and palatal to the remaining (PRF/CGF) membrane ${ }^{[5,13,14]}$. (Figure 3 (A, B and C)).

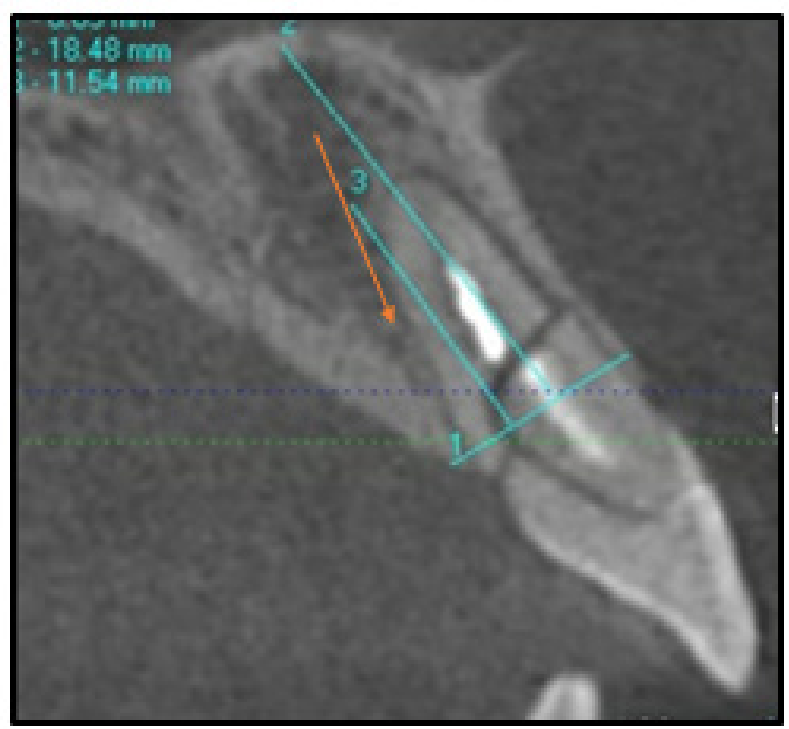

(A) root to be extracted. Measure the width and height of alveolar bone to define the actual size of implant needed (Figure 2 (A and B)).

\section{II- Surgical Technique:}

Scaling was performed for all patients and was instructed to rinse their mouths with chlorhexidine mouth wash (Orovex mouthwash- macro group pharmaceuticalsEgypt) immediately before operation for 2 minutes. Local anesthesia, articaine HCL and epinephrine $1: 20.000$ (Septodont, by Novocol Pharmaceutical of Canada, Inc.) was used for surgical procedures.

\section{In the Study Group:}

\section{Platelet Rich Fibrin Preparation:}

A convenient blood sample was collected from a peripheral venous blood from the patient in sterile $10 \mathrm{ml}$ tubes without the addition of an anticoagulant and centrifuged at 3000 revolutions per minute for 10 minutes and then progressively decelerated. (PRF) settles down between the platelet poor plasma (PPP) (supernatant) at the top and the red blood cells (RBC) at the bottom of the tube. After centrifuging, the sample was left undisturbed until the fibrin reached a viscous state. The fibrin layer was compressed with a metal cover to be converted to

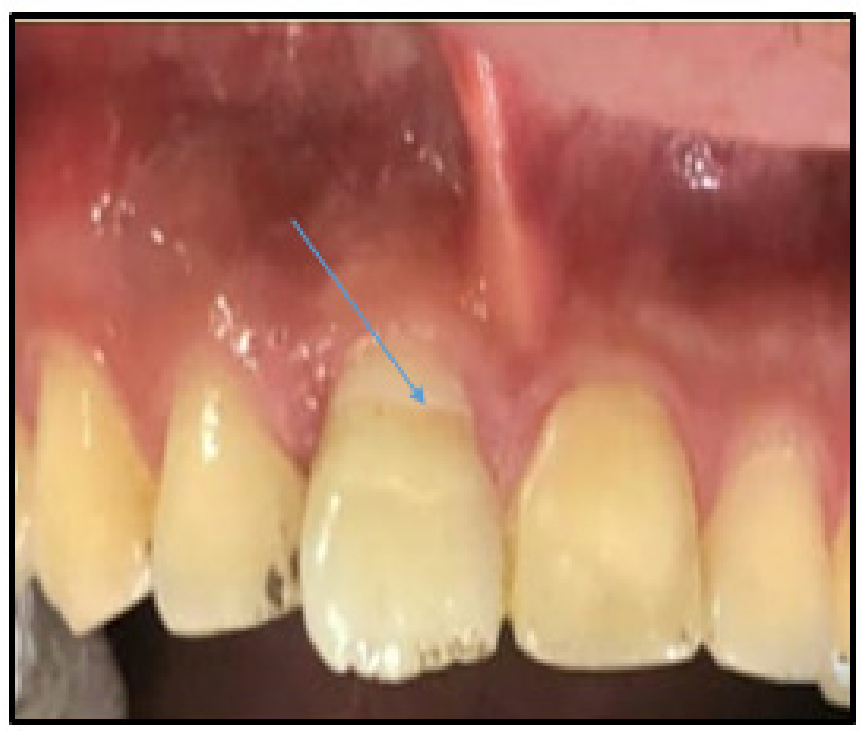

(B)

Figure 2:

(A): Photoradiograph showing cross section of pre-operative CBCT of horizontal fracture of the root ( red arrow ) \& the available width and height of alveolar ridge for implant placement.

(B): Photograph showing the affected tooth to be extracted ( blue arrow ). 


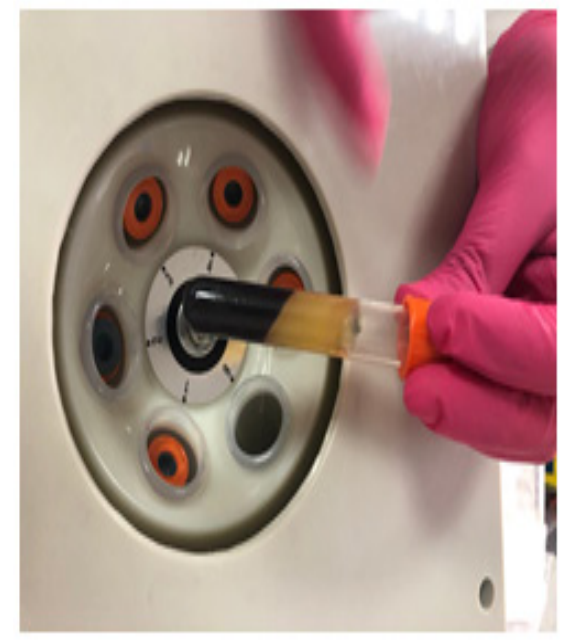

(A)

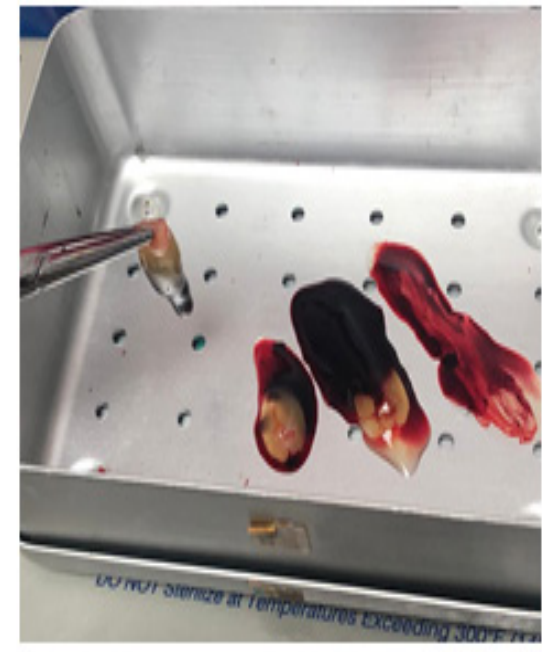

(B)

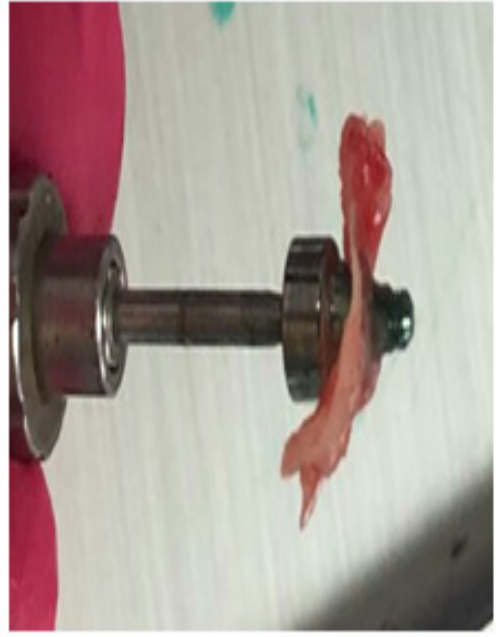

(C)

Figure 3: Photograph showing: Group (I),

(A) :Centrifuging apparatus.

(B) :Viscous state of ( PRF/CGF).

(C) :Insertion of healing abutment through (PRF/CGF) membrane.

\section{Surgical Procedure:}

During that time, the tooth was extracted in an atraumatic way with the aid of peristomes and a fine luxators. Scraping the walls of the socket was done with fine curettes to remove the periodontal tissue remnants. This procedure also triggers the regional acceleratory phenomenon, which is known to stimulate new bone formation. Then, according to the pre-operative (CBCT) images, sequential drilling with copious irrigation was carried out till the desired dimensions were achieved depending on the selected implant (Implant IMAX 4.1, NHSIC, Swiss). Manual key and ratchet were used for implant insertion. The implants were placed a little pit palatal and $3-5 \mathrm{~mm}$ beyond the root apex to achieve primary stability ${ }^{[15]}$.

In group I, a hole in the center of the (PRF/CGF) membrane was created in the middle of the membrane with cotton pliers. The prepared (PRF/CGF) membrane was placed through the top of a healing abutment (poncho technique) then placed on implant platform ${ }^{[5]}$. By this way, the residual gap between the socket walls and implant threads was grafted with (PRF/CGF) (Figure 4 (A, B and C)), then stabilized with a horizontal mattress suture around the healing abutment. However, in group II the sutures were performed around healing abutment without grafting.

\section{III- Post-operative Care:}

All patients were instructed to apply ice packs on the face, opposite to the surgical site for 10 minutes every 30 minutes, on the first day. Oral hygiene instructions which included rinsing with warm saline starting

24 hours postoperatively 5 times per day for the next 7 days. Amoxicillin $875 \mathrm{mg}$ combined with clavulanic acid $125 \mathrm{mg}$ antibiotic (Hibiotic, amoun pharmaceutical co. S.A.E. - Egypt) was prescribed every 12 hours for 3 days. Ibuprofen $600 \mathrm{mg}$. tablets (Brufen $600 \mathrm{mg}$ Tab. Abbott, Laboratories, Egypt) twice daily for three days. Antiseptic mouth rinses were prescribed the next day after surgery. (Orovex mouthwash-Macro Group Pharmaceuticals - Egypt) for one week. Overall healing process were followed up.

\section{IV-Restorative Protocol:}

Impression was taken using silicone impression materials after six months. Then, it was sent to the dental laboratory for the fabrication of the definitive restoration. The final crowns (porcelain fused to metal crown) were then cemented using resin modified glass ionomer cements. Excess cements were then was carefully removed and occlusion was checked using articulating papers (Figure 5 (A and B)).

\section{V-Follow up:}

Soft tissue and aesthetic outcomes were evaluated according to the PES two weeks after placement of the definitive restoration. Seven variables were assessed with a score of 2,1 or 0 with 2 being the best and 0 being the worst with the highest possible score attainable being

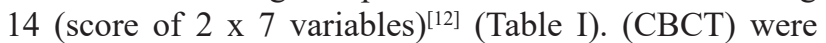
performed for all the patients immediate and six months postoperatively to assess labial bone height and thickness. (Figure 6 (A, B, C and D)). 
El-Sayed et al

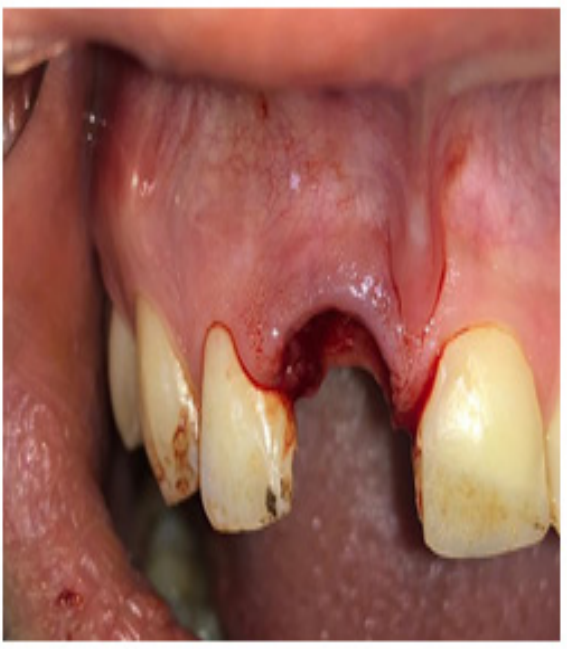

(A)

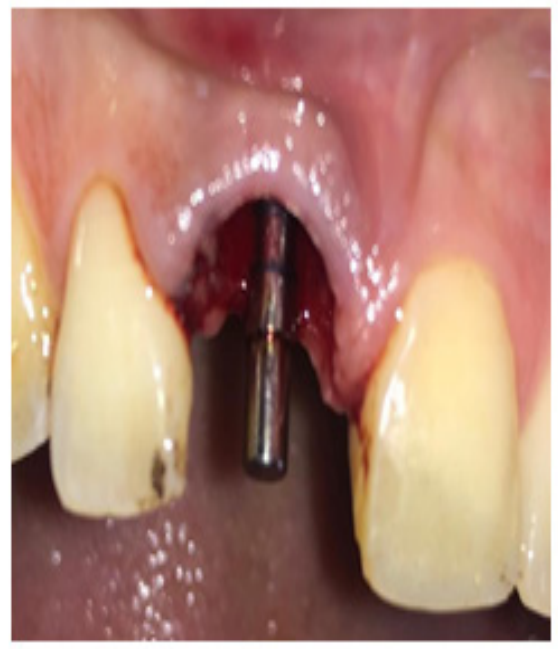

(B)

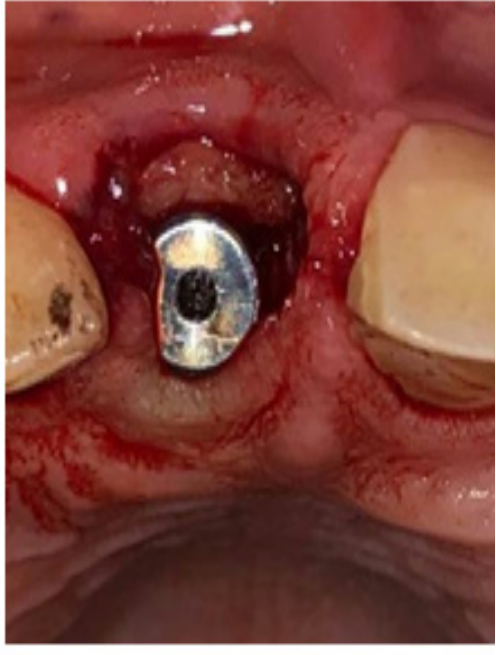

(C)

Figure 4: Photograph showing: Group (I),

(A) A traumatic extraction of upper central incisor.

(B) Implant insertion.

(C) Placement of (PRF/CGF) through the head of healing abutment around implant platform.

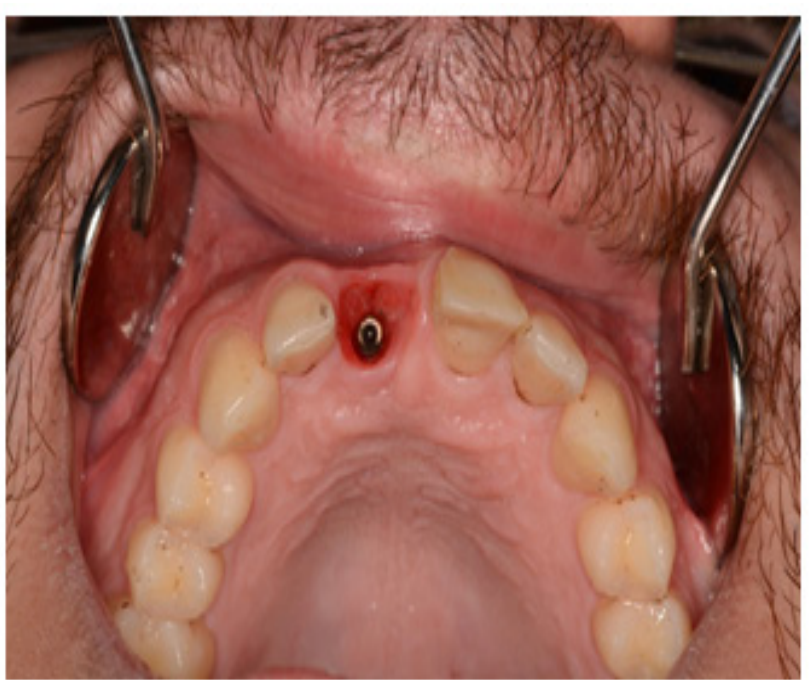

(A)

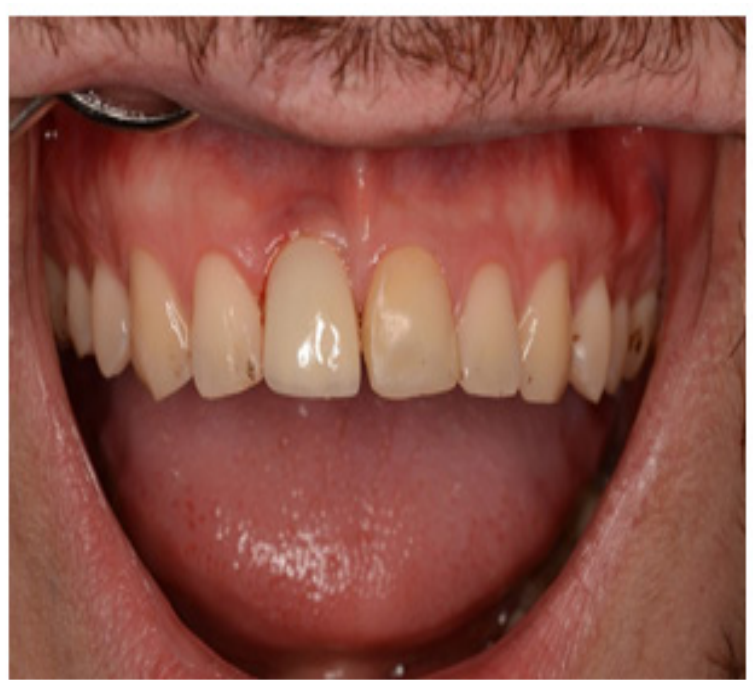

(B)

Figure 5: P Photograph showing : Group I;

(A): Six months post operatively. (Note: gingival tissue healing around the implant).

(B): Final crown cementation. 


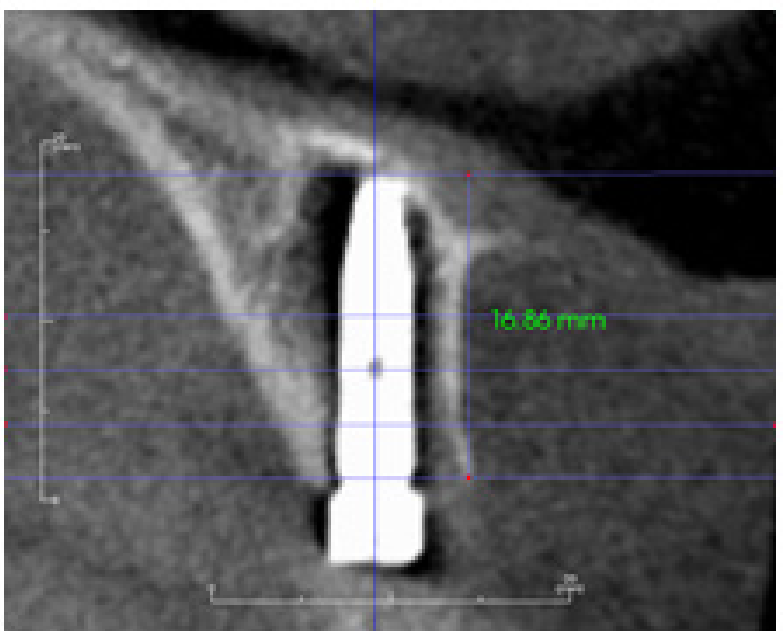

(A)

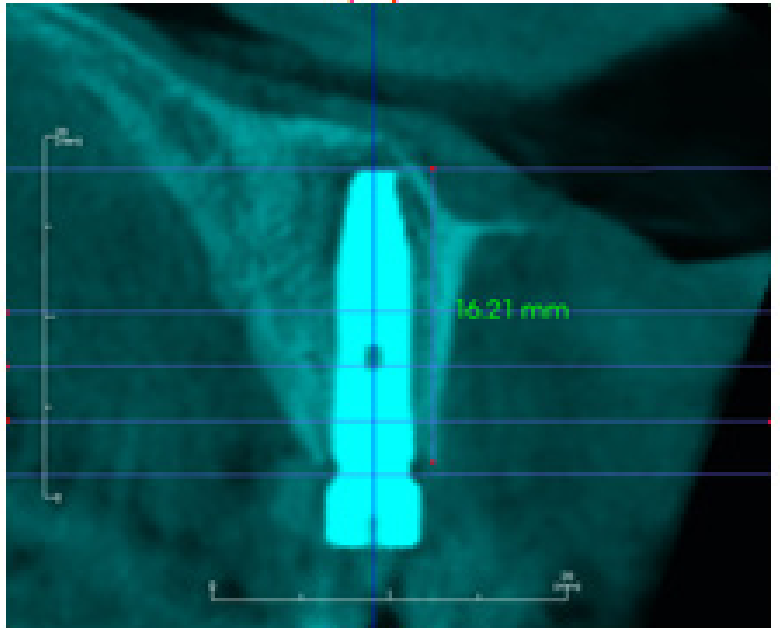

(C)

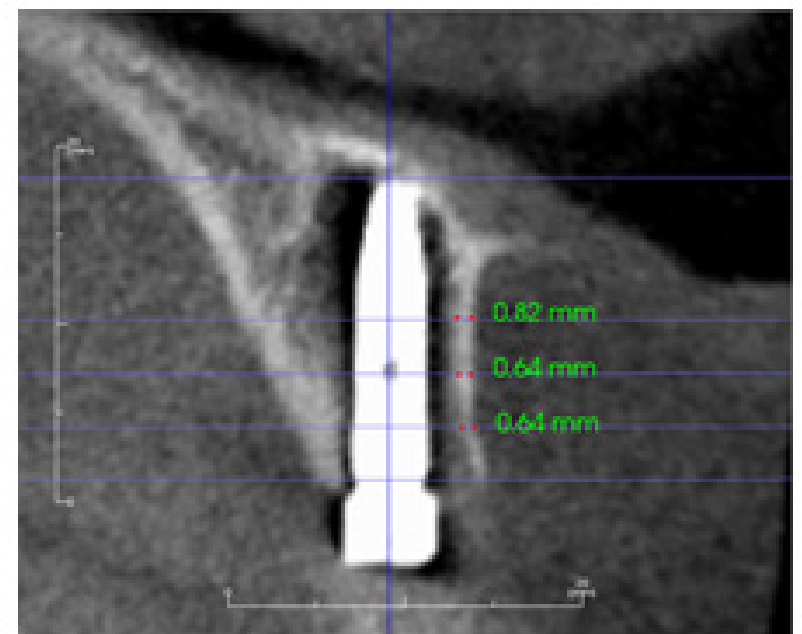

(B)

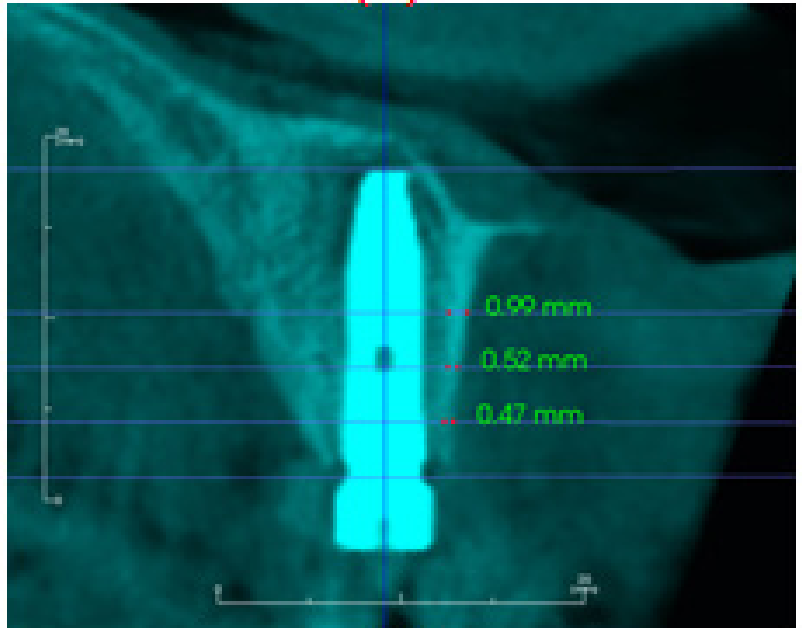

(D)

Figure 6: Group I:

Photoradiograph showing CBCT of: (A) Immediate post- operative labial bone height. (B) Immediate post-operative labial bone thickness at 3 planes. (C) Six months post-operative labial bone height. (D) Six months post operative labial bone thickness at 3 planes.

Table 1: Pink Esthetic Score Variables ${ }^{[12]}$ :

\begin{tabular}{|c|c|c|c|}
\hline Variable & $\mathbf{0}$ & 1 & 2 \\
\hline $\begin{array}{l}\text { 1- Mesial } \\
\text { papilla }\end{array}$ & absent & incomplete & present \\
\hline 2- Distal papilla & absent & incomplete & present \\
\hline $\begin{array}{l}\text { 3- Level of softt } \\
\text { tissue margin }\end{array}$ & $\begin{array}{c}\text { Major } \\
\text { Discrepancy } \\
>2 \mathrm{~mm}\end{array}$ & $\begin{array}{c}\text { Minor } \\
\text { Discrepancy } \\
1-2 \mathrm{~mm}\end{array}$ & $\begin{array}{c}\text { No } \\
\text { Discrepancy } \\
<1 \mathrm{~mm}\end{array}$ \\
\hline $\begin{array}{l}\text { 4- Soft tissue } \\
\text { contour }\end{array}$ & Unnatural & Fairly Natural & Natural \\
\hline $\begin{array}{l}\text { 5- Alveolar } \\
\text { process } \\
\text { deficiency }\end{array}$ & Obvious & Slight & None \\
\hline $\begin{array}{l}\text { 6- Soft tissue } \\
\text { color }\end{array}$ & $\begin{array}{l}\text { Obvious } \\
\text { Difference }\end{array}$ & $\begin{array}{l}\text { Moderate } \\
\text { Difference }\end{array}$ & No Difference \\
\hline $\begin{array}{l}\text { 7- Soft tissue } \\
\text { texture }\end{array}$ & $\begin{array}{l}\text { Obvious } \\
\text { Difference }\end{array}$ & $\begin{array}{l}\text { Moderate } \\
\text { Difference }\end{array}$ & No Difference \\
\hline
\end{tabular}

Data in this study was collected, tabulated and then statistically analyzed using Chi-square test and independent t-test. Results will be presented in the following section as:

1. Analysis of general demographic data.

2. Analysis of PES data (Clinical assessment).

3. Analysis of CBCT measurements (Radiographic assessment).

\section{RESULTS}

\section{Clinical Results:}

Clinical evaluation at 6 months revealed no complications associated with implant placement. Intraoral evaluation revealed good stability of the implant with 
the clinical characteristics of the peri-implant mucosa being indiscernible to those of the gingiva surrounding the neighboring teeth. None of the patients reported subjective adverse events such as pain or infection in the treated areas throughout the follow-up periods.

\section{1- General demographic data:}

Patient's ages ranged between 23 and 45 years $(32.13 \pm 7.3)$ of group I and 18 and 40 years $(31.4 \pm 8.1)$ of group II with no significant difference between both groups ( $P$-value 0.8$)$. The gender distribution showed female comprised $62.5 \%$ of group I and $50 \%$ of group II with no significant difference between both groups ( $P$-value 0.6$)$ (Table 2).

Table 2: Comparison between both groups regarding to demographic data:

\begin{tabular}{lccccc}
\hline & & $\begin{array}{c}\text { Study } \\
\text { group } \\
(\text { No. }=8)\end{array}$ & $\begin{array}{c}\text { Control } \\
\text { group } \\
(\mathbf{N o .}=\mathbf{8})\end{array}$ & P-value & Sig. \\
\hline \multirow{4}{*}{ Age } & $\begin{array}{c}\text { Mean } \\
\pm \text { SD }\end{array}$ & $32.13 \pm 7.3$ & $31.4 \pm 8.1$ & & \\
& Range & $23-45$ & $18-40$ & & \\
& Female & $5(62.5 \%)$ & $4(50 \%)$ & 0.8 & NS* \\
Gender & Male & $3(37.5 \%)$ & $4(50 \%)$ & & NS* \\
& & & & & \\
\hline
\end{tabular}

$* P>0.05$ : Non significant (NS), $P<0.05$ : Significant (S), $P<0.01$ : Highly significant (HS).

\section{2- Clinical assessment by Pink Esthetic Score:}

Regarding PES the mean values of assessments $1,2,3$ and 4 were $(11.8 \pm 1.6,10.3 \pm 1.9$, $11.1 \pm 0.99, \quad 10.6 \pm 1.2)$ respectively for study group and $(11.4 \pm 1.2,10.4 \pm 0.7,11 \pm 0.9,10.6 \pm 0.9)$ for control Group. P-Value showed non-significant difference between both groups for all 4 assessments. The mean average value for all 4 assessments was $(10.9 \pm 1.1)$ for study group and $(10.8 \pm 0.7)$ for control group with no significant difference between them with $(P$-Value $=0.8)($ Table 3$)$.

Cosyn et al. ${ }^{[16]}$ defined a PES score of equal or less than 7 to be an esthetic failure, greater or equal 8 to be acceptable, and greater or equal to 12 to be almost perfect. PES were recorded by four independent examiners not involved in any treatment. All photographs were scored twice with an interval of 1 week.

The study group was taken scores average from 8 to 14 which means acceptable to perfect result, the control group was taken scores average from 9 to 13 which also means acceptable to perfect result.
Table 3: Comparison between both groups regarding to PES assessment:

\begin{tabular}{cccccc}
\hline PES & & $\begin{array}{c}\text { Study group } \\
(\text { No. }=8)\end{array}$ & $\begin{array}{c}\text { Control } \\
\text { group } \\
\text { (No. }=8)\end{array}$ & P-Value & Sig. \\
\hline Assessment 1 & $\begin{array}{c}\text { Mean } \\
\pm \text { SD }\end{array}$ & $\begin{array}{c}11.8 \pm 1.6 \\
8-14\end{array}$ & $\begin{array}{c}11.4 \pm 1.2 \\
9-13\end{array}$ & 0.6 & NS* \\
& Range & & & & \\
Assessment 2 & Mean & $10.3 \pm 1.9$ & $10.4 \pm 0.7$ & 0.87 & NS* \\
& \pm SD & $8-13$ & $9-11$ & & \\
Assessment 3 & Meange & $11.1 \pm 0.99$ & $11 \pm 0.9$ & 0.79 & NS* \\
& \pm SD & $10-12$ & $10-12$ & & \\
Assessment 4 & Meange & $10.6 \pm 1.2$ & $10.6 \pm 0.9$ & 1.000 & NS* \\
& \pm SD & $9-12$ & $9-12$ & & \\
& Range & & & & \\
Average & Mean & $10.9 \pm 1.1$ & $10.8 \pm 0.7$ & 0.8 & NS* \\
& \pm SD & & & & \\
\hline
\end{tabular}

${ }^{*} P>0.05:$ Non significant $(\mathrm{NS}), P<0.05:$ Significant $(\mathrm{S})$, $P<0.01$ : Highly significant (HS).

\section{2- Radiographic assessment:}

\section{A) Labial bone thickness (Horizontal Bone Loss):}

Regarding the labial bone thickness immediately and six months post-operatively, the mean difference value was $(-0.29 \pm 0.32)$ for study group and $(-0.49 \pm 0.35)$ for control group. The comparison between both groups showed that the mean value of horizontal bone loss for the study group was lower than the control group. However, there was no statistically difference found between them regarding bone thickness $(P$-value $=0.24)($ Table 4$)$.

Table 4: Comparison between both groups regarding to labial bone thickness:

\begin{tabular}{|c|c|c|c|c|}
\hline $\begin{array}{c}\text { Labial bone } \\
\text { thickness } \\
\text { (Horizontal } \\
\text { bone loss) }\end{array}$ & $\begin{array}{l}\text { Study } \\
\text { Group } \\
(n=8)\end{array}$ & $\begin{array}{l}\text { Control } \\
\text { Group } \\
(\mathrm{n}=8)\end{array}$ & $p$-value & Sig. \\
\hline \multicolumn{5}{|c|}{ Immediately postoperative } \\
\hline $\operatorname{Mean} \pm$ SD & $1.3 \pm 0.43$ & $1.2 \pm 0.34$ & \multirow{2}{*}{$0.77 *$} & \multirow{2}{*}{ NS* } \\
\hline Range & $0.64-2.28$ & $0.75-2.18$ & & \\
\hline \multicolumn{5}{|c|}{6 months postoperative } \\
\hline \multirow{2}{*}{$\operatorname{Mean} \pm$ SD } & $1.1 \pm 0.37$ & $1.2 \pm 0.41$ & \multirow{2}{*}{$0.56^{*}$} & \multirow{2}{*}{ NS* } \\
\hline & $0.47-2.05$ & $0.83-1.90$ & & \\
\hline Mean Diff. & $-0.29 \pm 0.32$ & $-0.49 \pm 0.35$ & $0.24 *$ & NS* \\
\hline
\end{tabular}




\section{B) Labial bone height (Vertical Bone Loss):}

Regarding the labial bone height immediate and six months post-operatively, the mean difference value was $(-0.42 \pm 0.51)$ for study group and $(-1.1 \pm 0.77)$ for control group. The comparison between both groups showed that the mean value of vertical bone loss for the study group was lower than the control group. However, there was no statistically difference found between them regarding bone height $(P$-value $=0.53)($ Table 5$)$.

Table 5: Comparison between both groups regarding labial bone height:

\begin{tabular}{|c|c|c|c|c|}
\hline $\begin{array}{l}\text { Labial } \\
\text { bone } \\
\text { height } \\
\text { (Vertical } \\
\text { bone loss) }\end{array}$ & $\begin{array}{l}\text { Study group } \\
\qquad(\mathrm{n}=\mathbf{8})\end{array}$ & $\begin{array}{c}\text { Control } \\
\text { group }(n=8)\end{array}$ & $P$-value & Sig. \\
\hline \multicolumn{5}{|c|}{ Post Immediately } \\
\hline Mean \pm SD & $13.67 \pm 1.7$ & $12.93 \pm 0.89$ & \multirow{2}{*}{$0.29 *$} & \multirow{2}{*}{ NS* } \\
\hline Range & $12.37-16.86$ & $11.40-14.22$ & & \\
\hline \multicolumn{5}{|c|}{ Post 6 months } \\
\hline Mean \pm SD & $13.2 \pm 1.76$ & $11.8 \pm 1.0$ & \multirow{2}{*}{$0.65^{*}$} & \multirow{2}{*}{ NS* } \\
\hline Range & $11.50-16.21$ & $11.02-12.65$ & & \\
\hline Mean Diff. & $-0.42 \pm 0.51$ & $-1.1 \pm 0.77$ & $0.53 *$ & NS* \\
\hline
\end{tabular}

\section{DISCUSSION}

One of the greatest difficulties and pitfalls in inserting single post extracting implants in esthetic areas, especially in the anterior maxilla, is bone resorption triggered by the tooth extraction. Tooth extraction results in loss of the periodontal ligament, which with its vascular supply carries nutrition to the buccal bone plate. In the absence of this nourishment, the buccal bone plate undergoes physiologic resorption that mainly occurs within the first 4 to 6 months after tooth extraction. This bone resorption inevitably follows a contraction of the overlying soft tissues, which causes for the patient, and therefore for the clinician, an esthetic problem ${ }^{[17]}$.

Various strategies have been proposed to limit this physiologic resorption and therefore provide the patient with a better esthetic result: among them are socket preservation, gingival grafts, guided bone regeneration with membranes, and/or grafting materials ${ }^{[18]}$. However, no technique of bone preservation or entire generation of the extraction socket has been documented ${ }^{[19]}$.

In this study, all subjects were free from any systemic condition not to affect bone metabolism and periodontal status with the intention not to hinder osseointegration. We choose the maxillary anterior teeth because in the anterior regions, the resorption of the labial bone after tooth extraction leads to an esthetic problem, particularly with immediate implant placement ${ }^{[18]}$. Alveolar ridge resorption is partially attributed to loss of blood supply which derived from periodontal ligament of the tooth. The buccal plate of the teeth in anterior maxilla is very thin, leading to significant dimensional changes during immediate post extraction period ${ }^{[19,20]}$.

In the study group, we combined the concept of early implant placement with (PRF/CGF) and found partial bone healing that is consistent with later phases of socket healing ${ }^{[2]}$. Thus, re-entry could be performed timely enough before a large percentage of the alveolar ridge resorption has occurred. This accelerated waiting period increases patient satisfaction. The downside of conventional early placement is that only soft tissue healing has occurred in the socket and adequate primary implant stability in the immature site may be jeopardized ${ }^{[22]}$.

In the current study, (CBCT) was used preoperative, immediate and 6 months postoperatively. It is considered the gold standard radiograph to evaluate and compare the labial bone plate (LBP) alterations. Those findings are in agreement with Vandenberghe et al. ${ }^{[23]}$ research about detection of periodontal bone loss using digital intraoral and cone beam computed tomography images: an in vitro assessment of bony and/or infrabony defects, CBCT would allow accurate assessment of bone levels and a better description of infrabony defects than intraoral chargecoupled device $(\mathrm{CCD})$ images. The finding indicated that the current CBCT system may become more influential in the diagnosis of periodontal diseases and assessment of bone level, thickness and density. When compared with CBCT. Barkat et al. ${ }^{[24]}$ used CBCT as a radiographic evaluation to evaluate horizontal and vertical dimensional changes to the labial bone following maxillary anterior single immediate implant placement. It was done immediately after implant placement and after 4 and 7 months.

In this study, pink esthetic score (PES) was used in our assessment because of, according to Furhauser et al. ${ }^{[12]}$, PES reproducibly evaluates periimplant esthetic appearance of soft tissue around singletooth implants.

Soft tissue esthetic aspects are considered the key for success in implant restorations. There are some reports that documented the esthetics outcome using the PES criteria $^{[25,26]}$. Findings from those reports as regard to PES values are similar to the results obtained from the current study where most of the subjects at 6 months follow up period showed a higher PES values.

Statistical analysis showed that there was an increase in the value of PES assessment in study group than control group, but with no statistically significant difference found between them regarding assessment 1, 2, 3 and 4, 0.6, $0.87,0.79$ and 1.000 respectively (average $P$-value $=0.8$ ) (Table 3 ). This could be attributed to the relatively short period of follow up in the current study as well as the PES values from a 3 years prospective study conducted by Cosyn et al. ${ }^{[16]}$, who showed that $(5 / 24$ of all cases 
or $21 \%$ ) considered an esthetic failure (PES $<8$ ), ( $5 / 24$ of all cases or $21 \%$ ) considered esthetically perfect $(\mathrm{PES}=12)$ and the reminder $(14 / 24$ of all cases or $58 \%)$ considered as an acceptable esthetic.

The statistical analysis of radiographic result of the current study showed decreasing of labial bone thickness in both groups, post 6 months than post immediately but with no statistically significant difference $(\mathrm{P}-$ value $=0.24)$ between the two groups. The study group showed less decrease in labial bone thickness with mean value (- 0.29) than the control group with mean value (- 0.49) (Table 4). This result is agree with Abadzhiev et al. ${ }^{[27]}$ who concluded that from the radiological examination immediately after implantation and on every 6 months during the next 2 years, considerable bone loss in immediate implantation without (PRF) up to $12 \%$ in the first two years, which is equal up nearly to $5 \mathrm{~mm}$. Contrary in (PRF) technique during 2 years follow up bone loss is $2 \%$, which is equal nearly to $0.8 \mathrm{~mm}$.

Current evidence likes the results of Hürzeler et al..$^{[28]}$ who concluded that this proof of principle experiment confirms that using (PRF/CGF) in combination with immediate implant placement is able to achieve osseointegration without any inflammatory or resorption response. Therefore, this technique may have the potential to avoid the resorption of the (LBP) after tooth extraction.

As regard to the statistical analysis of radiographic result of (LBP) height for immediate and at 6 months postoperatively in both groups, the study group showed better results with less decrease in (LBP) height with mean value (- 0.42) than the control group with mean value (-1.1) with no statistically significant difference between them $(P$-value $=0.53)($ Table 5$)$. This results is important as crestal bone loss has been documented as one of the important factor that affects the long term prognosis of dental implant, therefore crestal bone preservation is thought to be of highly importance in the treatment planning for implant placement ${ }^{[29]}$.

Moreover, our study evaluated the amount and contour of (LBP) by using (PRF/GCF) in immediate implant technique. This was performed to avoid labial bone resorption and to achieve osseointegration without any inflammatory or resorption response as Triveni ${ }^{[30]}$ study stated that by preservation of alveolar ridge dimensions by the use of (PRF/GCF). One-year results showed effective ridge preservation to nearly original dimensions. A preliminary clinical and histomorphometry case report using (PRF/GCF) for extraction socket preservation revealed solid new bone formation 9 months after the procedure. The healed bone was able to support subsequent dental implant placement and loading ${ }^{[29,30]}$.

Autologous growth factors were introduced in dentistry with platelet rich plasma (PRP). The main drawback of (PRP) is the need for heterologous factors, such as bovine thrombin, for its preparation. Bovine thrombin may elicit coagulopathies associated with antibodies against specific clotting factors. Moreover, evidence on its efficacy remains equivocal in bone augmentation. The use of (PRF/ CGF) was introduced to overcome the complexity and possible health risks associated with (PRP), and to improve wound healing and bone regeneration. (31) In (PRF/GCF), platelets are entrapped in the fibrin matrix of (PRF) and growth factors such as (PDGF, TGF-b, VEGF, and IGF) are gradually released for a period of at least 7 days from the fibrin matrix.The temporal availability of growth factors prolongs their chemotactic properties and contributes to cell growth and proliferation. In preclinical studies, (PRF) has been shown to lead to similar results as autogenous bone in contained defects in rabbits. These attributes make $(\mathrm{PRF})$ an excellent matrix for socket regeneration ${ }^{[32]}$.

Our study seems promising technique in allowing dimensional stability around an implant site which was conducted to evaluate the clinical and radiographic efficacy of platelet rich fibrin (PRF/CGF) membrane used with immediately placed dental implants in the esthetic zone. All the implants were successfully osseointegrated over a one-year follow-up period with a success rate of $100 \%$ with insignificant change in the crestal bone level. These were in accordance with Sohn's Poncho technique ${ }^{[5]}$ which is a method to utilize the healing capacity of (PRF/CGF) autologous membranes in an open wound when performing localized guided bone regeneration techniques.

\section{CONCLUSION}

According to the aim of the present study, immediate implant placement in post-extraction socket by using (PRF/CGF) seems to be efficient in terms of minimizing hard and soft tissue alterations. However, no statistically significant differences in outcomes were found between the two groups.

\section{CONFLICT OF INTEREST}

The authors declare no conflict of interest.

\section{REFERENCES}

1. Kenawy M H, El Shinnawi U M , Salem AM, Ahmed F H. Efficacy of platelet rich fibrin (PRF) membrane in immediate dental implant. Journal of Dentistry 2014; 1 (3): 78 - 84 .

2. Dohan Ehrenfest DM, Rasmusson L, Albrektsson T. Classification of platelet concentrates: From pure platelet-rich plasma (P-PRP) to leucocyte- and platelet-rich fibrin (L-PRF). Trends Biotechnol. 2009; 27: 158 - 167.

3. Anitua E, Andia I, Ardanza B, Nurden P, Nurden AT. Autologous platelets as source of proteins for healing and tissue regeneration. Thromb Haemost 2004; 91 (1): 4 - 15. 
4. Gassling V, Hedderich J, Acil Y, Purcz N, Wiltfang J, Douglas T. Comparison of platelet rich fibrin and collagen as osteoblast-seeded scaffolds for bone tissue engineering applications. Clin Oral Implants Res 2013; 24 (3): 320 - 328.

5. Sohn DS, Kim HG .Simplified ridge and extraction socket augmentation using Sohn's Poncho technique .The Journal of Implant \& Advanced Clinical Dentistry. 2018; 10 (2): 16 - 38.

6. Magalhães VS, Ribeiro RA, Amaral JM, Pimentel AC, Paulim LA, Roman-Torres CV. The use platelet rich fibrin in dental implants: A literature review. Trends in Transplant. 2018; 11 (2): 1 - 3.

7. Artzi Z, Tal H, Dayan D. Porous bovine bone mineral in healing of human extractiosockets.Part 1:histomorphometric evaluations at 9 months. J Periodontol. 2000; 71: 1015 - 1023.

8. Carmagnola D, Adriaens P, Berglundh T. Healing of human extraction sockets filled with Bio-Oss. Clin Oral Implants Res. 2003; 14: 137 - 143.

9. Kamburoğlu K, Murat S, Kılıç C, Yüksel S, Avsever H, Farman A. Accuracy of CBCT images in the assessment of buccal marginal alveolar peri-implant defects: effect of field of view. Dentomaxillofacial Radiology. 2014; 43 (4): 201303 - 32.

10. Monje A, Suarez F, Galindo-Moreno P, GarcíaNogales A, Fu JH, Wang HL. A systematic review on marginal bone loss around short dental implants $(<10 \mathrm{~mm})$ for implant- supported fixed prostheses. Clinical oral implants research. 2014; 25 (10): 1119- 24.

11. Tettamanti S, Millen C, Gavric J, Buser D, Belser UC, Brägger U. Esthetic evaluation of implant crowns and peri-implant soft tissue in the anterior maxilla: comparison and reproducibility of three different indices. Clinical implant dentistry and related research. 2016; 18 (3): 517 - 26.

12. Fürhauser R, Florescu D, Benesch T, Haas R, Mailath G, Watzek G. Evaluation of soft tissue around single-tooth implant crowns: The pink esthetic score. Clinical oral implants research. 2005; 16 (6): 639 - 44.

13. Denissen HW, Kalk W, Veldhuis HA, van Waas MA. Anatomic consideration for preventive implantation. Int $\mathrm{J}$ Oral Maxillofac Implants 1993; 8 (2): 191 - 196.
14. Kotsakis GA, Boufidou F, Hinrichs JE, Prasad HS, MS ,Rohrer M, Tosios KI. Extraction socket management utilizing platelet rich fibrin: A proofof-principle study of the "Accelerated-early implant placement" concept. J Oral Implantol. 2016; 42 (2): 164 - 168 .

15. Buser D, Weber HP, Lang NP. Tissue integration of non-submerged implants. 1-year results of a prospective study with 100 ITI hollow-cylinder and hollow-screw implants. Clin Oral Implants Res. 1990; 1: $33-40$.

16. Cosyn J, Eghbali A, De Bruyn H, Collys K, Cleymaet R, De Rouck T. Immediate single-tooth implants in the anterior maxilla: 3-year results of a case series on hard and soft tissue response and aesthetics. Journal of clinical periodontology. 2011; 38 (8): 746 - 53.

17. Han CH, Park KB, Mangano FG. The modified socket shield technique. Journal of Craniofacial Surgery. 2018; 29 (8): 2247 - 54.

18. Mangano F, Mangano C, Ricci M, Sammons RL, Shibli JA, Piattelli A. Single-tooth Morse taper connection implants placed in fresh extraction sockets of the anterior maxilla: An aesthetic evaluation. Clinical oral implants research. 2012; 23 (11): 1302 - 7.

19. Braut V, Bornstein MM, Lauber R, Buser D Bone dimensions in the posterior mandible: A retrospective radiographic study using cone beam computed tomography. Part 1 Analysis of dentate sites. International Journal of Periodontics and Restorative Dentistry.2012; 32 (2): 175 - 84.

20. Zekry A, Wang R, Chau AC, Lang NP. Facial alveolar bone wall width-a cone-beam computed tomography study in asians. Clinical oral implants research. 2014; 25 (2): 194 - 206.

21. Hammerle CH, Chen ST, Wilson TG. Consensus statements and recommended clinical procedures regarding the placement of implants in extraction sockets. Int J Oral Maxillofac Implants. 2004; 19: $26-28$.

22. Barewal RM, Stanford C, Weesner TC. A randomized controlled clinical trial comparing the effects of three loading protocols on dental implant stability. Int J Oral Maxillofac Implants. 2012; 27: $945-956$

23. Vandenberghe B, Jacobs R, Yang J. Detection of periodontal bone loss using digital intraoral 
and cone beam computed tomography images: An in vitro assessment of bony and/or infrabony defects. Dentomaxillofacial Radiology. 2008; 37 (5): 252 - 60.

24. Barakat DA, Hassan RS, Eldibany RM. Evaluation of the Socket Shield Technique For Immediate Implantation. Alexandria Dental Journal. 2017; 42: 155 - 61.

25. Juodzbalys G, Wang HL. Soft and hard tissue assessment of immediate implant placement: a case series. Clinical oral implants research. 2007; 18 (2): 237 - 43.

26. Raes F, Cosyn J, Crommelinck E, Coessens $P$, De Bruyn H. Immediate and conventional single implant treatment in the anterior maxilla: 1-year results of a case series on hard and soft tissue response and aesthetics. Journal of clinical periodontology. 2011; 38 (4): 385 - 94.

27. Abadzhiev M, Nenkov P, Velcheva P. Conventional immediate implant placement and immediate placement with socket-shield technique-which is better. International Journal of Clinical Medicine Research. 2014; 1: 176 - 80.

28. Hurzeler MB, Zuhr O, Schupbach P, Rebele SF, Emmanouilidis N, Fickl S. The socket-shield technique: a proof- of-principle report. Journal of Clinical Periodontology. 2010; 37 (9): 855 - 62.

29. Covani U, Cornelini R, Barone A. Bucco-lingual bone remodeling around implants placed into immediate extraction sockets: a case series. Journal of Periodontology. 2003; 74 (2): 268 - 73.

30. Triveni MG, TarunKumar AB, Jain V, Mehta DS. Alveolar ridge preservation with -TCP graft and platelet- rich fibrin. International Journal of Oral Implantology and Clinical Research. 2012; 3 (2): 96 - 100.

31. Dohan Ehrenfest DM, de Peppo GM, Doglioli P, Sammartino G. Slow release of growth factors and thrombospondin-1 in Choukroun's platelet rich fibrin (PRF): a gold standard to achieve for all surgical platelet concentrates technologies. Growth Factors. 2009; 27: 63 - 69.

32. Kotsakis GA, Boufidou F, Hinrichs JE, Prasad HS, Rohrer M, Tosios KI. Extraction socket management utilizing platelet rich fibrin: A Proofof-Principle Study of the "Accelerated-Early Implant Placement" Concept Journal of Oral Implantology. 2016; XLII (2): 1 - 5. 